\title{
ANGIOMATOUS TYPE MENINGIOMA IN A MALE PATIENT
}

\author{
Lenny Arinda ${ }^{1}$, Restu Susanti ${ }^{2}$, Syarif Indra²
}

Abstrak

Meningioma merupakan tumor otak primer yang paling sering dijumpai, ${ }^{1}$ namun meningioma angiomatosa merupakan subgrup meningioma yang sangat jarang $(2,1 \%) .{ }^{2}$ Meningioma umumnya terjadi pada perempuan, namun khusus tipe angiomatosa lebih sering pada laki-laki. Dilaporkan kasus meningioma angiomatosa pada laki-laki berusia 56 tahun, yang didiagnosis berdasarkan gejela klinis, pencitraan, dan gambaran histopatologi yang khas. Pasien dilakukan operasi kraniektomi reseksi tumor total dilanjutkan pemasangan tulang kranium kembali 6 bulan kemudian yang mengalami perbaikan klinis.

Kata Kunci: Meningioma angiomatosa, laki-laki, reseksi, tumor

\section{Abstract}

Meningiomas are the most common primary brain tumors, ${ }^{1}$ but angiomatous meningioma is a rare subgroup of meningiomas $(2,1 \%) .^{2}$ Meningioma generally occurs in women, but specifically the type of angiomatosa is more common in men. Here, we are presenting a case of 56 years old male patient presented, diagnosed by symptoms,radio- imaging, and typical histopathological features. Patient underwent craniectomy tumor removal, reimplantasi of skull 6 months later, and got clinical enhancement.

Key words: Angiomatous Meningioma, male,resection, tumor

Affiliasi penulis: 1. PPDS Neurologi Fakultas Kedokteran Universitas Andalas, 2. Bagian Neurologi FK Unand/ RSUP Dr. M. Djamil, Padang

Korespondensi: Lenny Arinda e-mail: lerinata_htg@yahoo.com Telp/HP :081361757687

\section{PENDAHULUAN}

Meningioma merupakan tumor otak primer yang paling sering dijumpai, yaitu sekitar $36 \%{ }^{1}$ Salah satu subgrup meningioma yang sangat jarang adalah meningioma angiomatosa, yaitu $2,1 \%$ dari seluruh kasus meningioma, yang memiliki predileksi di regio konveksitas serebri. Berbeda dengan meningioma pada umumnya, meningioma tipe ini lebih banyak pada laki-laki. ${ }^{2}$ Tatalaksana utama adalah reseksi tumor total yang akan memberikan prognosis yang baik. Berikut dilaporkan kasus mengioma angiomatosa dengan komplikasi kejang yang dilakukan kraniektomi pengangkatan tumor, namun memiliki keluaran yang baik.

\section{KASUS}

Pasien laki-laki 56 tahun datang ke IGD RSUP Dr. M Djamil dengan keluhan lemah anggota gerak kanan sejak 6 hari sebelum masuk RS. Keluhan diawali dengan nyeri kepala sejak 6 bulan sebelumnya. Kepala terasa seperti ditekan di bagian kiri dan bertambah berat. Pasien juga mengeluhkan mudah lupa dalam mengingat hal-hal baru. Pada 6 hari sebelum masuk RS, tangan dan kaki kanan terasa lemah disertai mulut mencong, bicara pelo, dan kejang. Kejang diawali kepala menoleh ke kanan, kelojotan pada tubuh sisi kanan diikuti seluruh tubuh selama \pm 1 menit. Saat kejang pasien tidak sadar, lidah tergigit, dan mengompol. Kejang terjadi sebanyak tiga kali, sadar di antara kejang. Pasien seorang PNS dan tidak merokok.

Pada pemeriksaan fisik didapatkan GCS 15, funduskopi papil edema ODS, paresis N.VII dan N.XII dekstra tipe sentral, dan kekuatan motorik 4 pada ekstremitas atas bawah, lain-lain dalam batas normal. Pemeriksaan Montreal Cognitive Assesment Versi Indonesia (MOCA-Ina) didapatkan skor 19. Hasil CT 
scan tanpa kontras (Gambar 1) didapatkan lesi isodens disertai hipodens di sekitarnya di frontotemporal kiri yang mengobliterasi ventrikel lateral kiri dengan pergeseran garis tengah ke kanan $>5 \mathrm{~mm}$ ke kanan. Kesan suatu tumor intrakranial dengan edema perifokal luas suspek meningioma maligna di frontotemporal kiri.

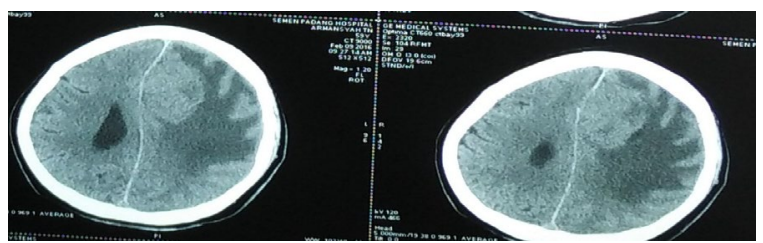

Gambar 1. CT Scan Kepala Tanpa Kontras

Hasil MRI kepala dengan kontras (Gambar 2) tampak lesi hipointens pada T1W1, yang menjadi hiperintens pada T2W2 di falks sisi kiri dan menyangat pascapemberian kontras, homogen, dan berbatas tegas. Tampak juga lesi hipodens di sekitar lesi tersebut yang menyebabkan pergeseran ke sisi kanan.

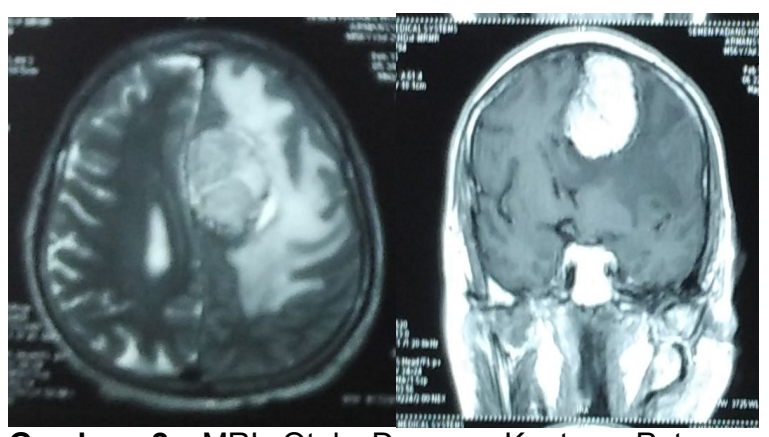

Gambar 2. MRI Otak Dengan Kontras Potongan Sagital T2W2 (kiri), Potongan Koronal T1W1 dengan kontras (kanan)

Pasien dilakukan operasi craniectomy tumor removal dan dekompresi. Intraoperatif terjadi perdarahan hebat dan edema otak, 24 jam kemudian pasien sadar dengan hemiplegia dekstra. Dilakukan CT scan kepala tanpa kontras (Gambar 3) untuk evaluasi dengan hasil sugestif meningioma residif.

Pasien dilanjutkan perawatan di bangsal Saraf dengan komplikasi trombosis vena dalam (deep vein thrombosis/DVT) dan kejang yang sudah membaik. Satu bulan kemudian kelemahan anggota gerak kanan juga perbaikan. Pasien dilakukan operasi pemasangan tulang kranium pada bulan ke-6. Saat kontrol, pasien sudah tidak kejang, dengan kekuatan motorik kanan $4^{+}$.

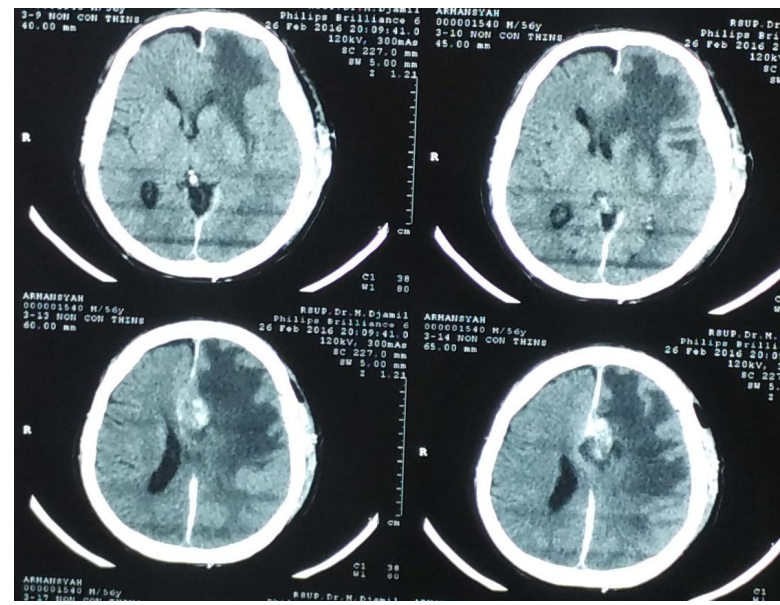

Gambar 3. CT Scan Kepala Tanpa Kontras Pascaoperasi

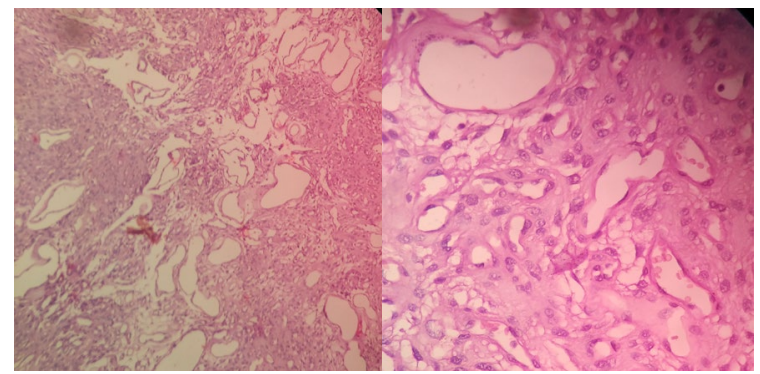

Gambar 4. Hasil Pemeriksaan Histopatologi: Angiomatous Meningioma WHO Grade I.

\section{PEMBAHASAN}

Insiden meningioma mencapai 7 per 100.000 orang pertahun, dan dua kali lebih banyak pada wanita. Berbeda dengan mengioma pada umumnya, angiomatous meningioma lebih banyak terjadi pada pria. Meningioma umumnya terjadi pada usia 40-70 tahun, dan jarang terjadi pada anak (2\%). ${ }^{2-3}$ Pada kasus ini pasien laki-laki berusia 56 tahun, sesuai dengan epidemiologi angiomatous meningioma.

Penyebab meningioma belum diketahui, tetapi diduga berhubungan dengan faktor genetik, radiasi dan hormon seks sebagai faktor risiko. Sekitar $50-75 \%$ penderita meningioma mengalami kehilangan material genetik dari lengan panjang kromosom 22, pada lokus gen untuk neurofibromatosis 2 (NF2) yang merupakan gen supresor tumor pada 22Q12. Studi terakhir menemukan mutasi gen non NF2 pada meningioma yaitu mutasi gen SMO (L412F dan W535L), AKT1 (E17K), KLF4 (K409Q), dan TRAF7. ${ }^{3-4}$

Meningioma juga mempunyai reseptor hormon seks dan ligan yang lain seperti progesteron, androgen, glukokortikoid, epidermal derived growth factor, insulin-like growth factor 1 and 2, transforming growth factor-beta (TGF-b), interferon-a, fibroblast growth factor-1, estrogen, dan prolaktin. ${ }^{5}$ Pada pasien 
ini belum memungkinkan untuk dilakukan eksplorasi faktor risiko dikarenakan keterbatasan fasilitas.

Berdasarkan klasifikasi WHO tahun 2007, meningioma dibagi menjadi grade I (benigna), grade II (atipikal), dan grade III (anaplastik). Meningioma grade I dengan prevalensi tertinggi yaitu $85-95 \%$ dengan angka rekurensi dalam 5 tahun sebesar $3 \%$. Angiomatous meningioma merupakan subgrup dari meningioma grade I.6-7 Pasien ini termasuk meningioma grade I (benigna).

Pemeriksaan penunjang radiologi pada meningioma dapat berupa foto $x$-ray, Ct scan kepala dan MRI. Pada foto $x$-ray dapat ditemukan gambaran khas, yaitu hiperostosis, peningkatan vaskularisasi dan kalsifikasi. Pada CT scan tanpa kontras, meningioma akan memberikan gambaran isodense hingga sedikit hyperdense dan kalsifikasi. Sedangkan CT scan dengan kontras akan memberikan gambaran massa yang menyangat kontras dengan kuat dan homogen. Gambaran hiperostosis, edema peritumoral dan nekrosis sentral juga dapat dijumpai. Gambaran khas pada Ct scan kepala adalah adanya dural tail yaitu duramater yang melekat pada tulang. Pada MRI dengan T1W1 umumnya memberikan gambaran isointense sedangkan beberapa lainnya memberikan gambaran hypointense dibandingkan dengan gray matter. Pada T2W2, meningioma juga umumnya menunjukkan gambaran isointense dengan beberapa yang hyperintense karena kandungan airnya yang tinggi terutama pada jenis meningothelial, yang hipervaskular, dan yang agresif. ${ }^{7-8}$ Pada pasien ini dilakukan Brain CT Scan Tanpa Kontras dengan gambaran lesi isodens tidak tampak kalsifikasi ataupun duraltail. Pada MRI otak pasien ini baik T1W1 dengan gambaran hipointens dan pada T2W2 dengan gambaran slights hiperintens.

Pemeriksaan pencitraan tidak dapat membantu membedakan klasifikasi meningioma, namun pada angiomatous meningioma, meningothelial, anaplastik dan mikrositik meningioma akan terlihat edema perilesi yang lebih luas dibandingkan subgrup meningioma lainnya. ${ }^{2}$ Pada pasien ini baik pencitraan pre dan post operasi ditemukan edema yang luas.

Bagaimanapun juga pemeriksaan pencitraan dapat memberikan gambaran yang bervariasi dan tidak dapat digunakan untuk diagnosis akhir, sehingga diperlukan biopsi segera. Pada pemeriksaan histopatologi angioamatous meningioma didapatkan well-formed vascular, sinusoid atau kapiler yang lebih dominan. Berdasarakan histopatologi angiomatous meningioma dibedakan menjadi dua subtipe yaitu mikrovaskular (lebih dari 50\% vaskular dengan diameter $<30 \mu$ ) dan subtipe makrovaskular (lebih dari $50 \%$ vaskular dengan diameter $>30 \mu) .{ }^{2}$ Pada hasil pemeriksaan histopatologi pasien ini tampak banyak pembuluh darah dengan ukuran bervariasi.

Penatalaksanaan pada meningioma dapat berupa embolisasi, pembedahan, radiosurgery, dan radiasi. Pembedahan merupakan terapi utama pada penatalaksanaan semua jenis meningioma. Sebaiknya reseksi yang dilakukan meliputi jaringan tumor, batas duramater sekitar tumor, dan tulang kranium apabila terlibat. 8

Beberapa jenis meningioma terutama malignan umumnya memiliki vaskularisasi yang tinggi, sehingga embolisasi preoperatif mempermudah tindakan reseksi tumor. Embolisasi preoperatif dilakukan pada tumor yang berukuran kurang dari 6 $\mathrm{cm}$ dan dengan pertimbangan keuntungan dibandingkan dengan resiko dari embolisasi. ${ }^{9}$

Radioterapi disarankan sebagai terapi adjuvan pada reseksi inkomplit, tumor rekuren dan atau grade tinggi, serta sebagai terapi utama pada beberapa kasus seperti meningioma saraf optik dan beberapa tumor yang tidak dapat direseksi. Modalitas lain pada terapi meningioma adalah stereotactic radiosurgery. Stereotactic radiosurgery umumnya dilakukan pada tumor jinak berukuran kecil atau yang tidak dapat dioperasi dan pada tumor residual atau rekuren setelah operasi. Terapi ini disarankan pada meningioma berukuran dibawah $3 \mathrm{~cm}$ yang melibatkan skull base dan sinus kavernosus dengan tujuan mencegah progresi tumor.9-10 Pada kasus ini tidak didahului embolisasi preoperatif, namun pada kasus ini dilakukan dekompresi akibat oedem hebat pasca reseksi tumor. Berdasarkan kriteria Simpson kasus ini termasuk grade I, dengan rekurensi $9 \%$ dalam 10 tahun.

Pada pasien ini dilakukan reseksi total dengan penyulit perdarahan masif dan oedem serebri hebat intraoperatif. Hal ini juga tampak pada 
pemeriksaan Brain CT scan yang dilakukan 1 minggu post-operatif, dimana masih tampak edema serebri.

Terdapat beberapa komplikasi post operasi pada pasien ini diantaranya DVT. Penatalaksanaan DVT pada pasien ini dengan pemberian Low Molecular Weight Heparin (LMWH) selama 5 hari dan dilanjutkan dengan pemberian simarc $1 \times 5 \mathrm{mg}$ po selama 3 bulan. Berdasarkan CHEST Guideline 2016, pasien DVT pada tungkai, emboli paru dan tidak menderita kanker lebih dianjurkan pemberian antikoagulan dabigatran, rivaroxaban, apixaban atau edoxaban selama 3 bulan setelah pemberian parenteral antikoagulan (grade 2B). ${ }^{11}$

Risiko terjadinya Venous thromboembolism (VTE) pada pasien meningioma tiga kali lebih besar dibanding tumor otak lainnya. Hal ini dikaitkan dengan terjadinya hiperkoagulasi yang diinduksi tumor. Faktor koagulasi dapat teraktivasi melalui permukaan meningen atau akibat kerusakan endotel vaskular yang disebabkan pembedahan. Tindakan operasi otak melepaskan tromboplastin di otak. Selain itu imobilisasi post operasi, durasi operasi yang lama, dan kelemahan tungkai pra operasi dapat menyebabkan stasis vena. Selain itu penggunaan steroid dosis tinggi dilaporkan turut berkontribusi. ${ }^{12}$ Studi retrospektif yang dilakukan Hofnagel dkk (2014) menunjukkan 5\% pasien meningioma yang dilakukan tindakan operatif memiliki komplikasi DVT meskipun telah mendapat terapi heparin sebagai profilaksis VTE. ${ }^{13}$ DVT saya bahas karena merupakan komplikasi yang muncul pada kasus ini.

Selain itu, terdapat kejang berulang pada pasien ini. Kejang yang muncul pada pasien ini merupakan epilepsi simptomatik (brain tumor-related epilepsy). Hingga saat ini belum ada evidence-based guidelines yang spesifik untuk penatalaksanaan brain tumor-related seizures, namun sebagian besar ahli menyatakan levetiracetam merupakan first drug of choice. Levetiracetam terbukti memiliki aktivitas antikonvulsan yang memuaskan dengan efek samping minimal, bahkan jika dikombinasi dengan anti kejang lainnya. Selain itu, Levetiracetam dapat dititrasi dengan cepat, diberikan parenteral dan tidak memiliki interaksi yang signifikan dengan obat kemoterapi. ${ }^{14}$ Namun pada pasien ini diberi terapi phenytoin. Hal ini atas pertimbangan biaya dan ketersediaan obat anti kejang. Meskipun demikian phenytoin merupakan terapi yang efektif untuk bangkitan fokal ataupun bangkitan umum sekunder (Level A). Pemberian anti epilepsi pada pasien ini dilanjutkan hingga tiga-lima tahun bebas kejang.

\section{SIMPULAN}

Meningioma merupakan tumor jinak intrakranial yang paling banyak, dimana mengioma angiomatosa merupakan subgrup meningioma grade I yang jarang. Pasien ini didiagnosis sebagai meningioma berdasarkan klinis, pemeriksaan pencitraan, dan pemeriksaan histopatologi. Pada pasien ini dilakukan craniectomy tumor removal. Mengioma angiomatosa memiliki keluaran yang baik dengan tingkat rekurensi yang kecil. Terdapat beberapa komplikasi pada pasien ini yaitu intraoperatif (perdarahan masif), post-operatif (DVT dan brain tumor-related epilepsy). Komplikasi ini dapat ditatalaksana dengan baik dan pasien mengalami perbaikan klinis.

\section{DAFTAR PUSTAKA}

1. Marciscano AE, Stemmer-Rachamimov AO, Niemierko A, Larvie M, Curry WT, Barker FG, dkk. Benign meningiomas (WHO Grade I) with atypical histological features: correlation of histopathological features with clinical outcomes. J Neurosurg. 2016; 124:106-14.

2. Rathod GB, Vyas K, Shinde P, Goswami SS, Tandan RK. Angiomatous meningioma in 49 years old male-A rare case report. Int $\mathrm{J}$ Curr Microbiol App Sci. 2014; 3(11):256-60.

3. Wöhrer A. Epidemiology of meningioma. European Association of Neuro Oncology Magazine. 2013; 3(3):95-6.

4. Abedalthagafi MS, Merrill PH, Bi WL, Jones RT, Listewnik ML, Ramkissoon SH, dkk. Angiomatous meningiomas have a distinct genetic profile with multiple chromosomal polysomies including polysomy of chromosome 5. Oncotarget. 2014; 5(21):10596-606.

5. Rhun EL, Taillibert S, Chamberlain MC. Systemic therapy for recurrent meningioma. Expert Review of Neurotherapeutics. 2016; 16(8):889-901.

6. Bi WL, Zhang M, Wu WW, Mei Y, Dunn FI. Meningioma genomics: diagnostic, prognostic, 
and therapeutic applications. Frontiers in

Surgery. 2016; 3(1):1-8.

7. Cossu G, Messerer M, Parker F, Levivier M, Daniel RT. Meningiomas' management: an update of the literature. Dalam: Agrawal A, editor. Neurooncology-Newer Developments. InTech; 2016. Hal.361-79.

8. Chamberlain MC. Meningiomas. Dalam: Norden, Reardon, Wen, editor. Primary central nervous system tumors. Humana Press; 2011. Hal.35570.

9. Levacic D, Nochlin D, Steineke T, Landolfi JC. Management of malignant meningiomas. Dalam: Monleon, editor. Meningiomas-Management and surgery. D InTech: 2012. Hal.1-34.

10. Goldbrunner R, Minniti G, Preusser M, Jenkinson M, Sallabanda K, Houdart E, dkk. EANO guidelines for the diagnosis and treatment of meningiomas. Lancet Oncol. 2016; 17(9):e38391.

11. Kearon C, Akl E, Ornelas J, Blaivas A, Jimenez $\mathrm{D}$, Bounameaux $\mathrm{H}$, dkk. Antithrombotic therapy for VTE disease CHEST guideline and expert panel report. CHEST. 2016; 149(2):315-52.

12. Eisenring CV, Neidert MC, Bove DS, Held L, Sarnthein J, dkk. Reduction of thromboembolic events in meningioma surgery: a cohort study of 724 concecutive patients. Plos ONE. 2013; 8(11):e79170.

13. Hoefnagel D, Kwee LE, Putten EH, Kros JM, Dirven CM, dkk. The incidence of postoperative thromboembolic complications following surgical resection of intracranial meningioma. A retrospective study of large single center patient cohort. Clinical Neurology and Neurosurgery 123; 2014: 150-54.

14. Froscher W, Kirschstein T, Rosche J. Anticonvulsant therapy in brain-tumor related epilepsy. Journal of Epileptology. 2016; 24(1):4156. 